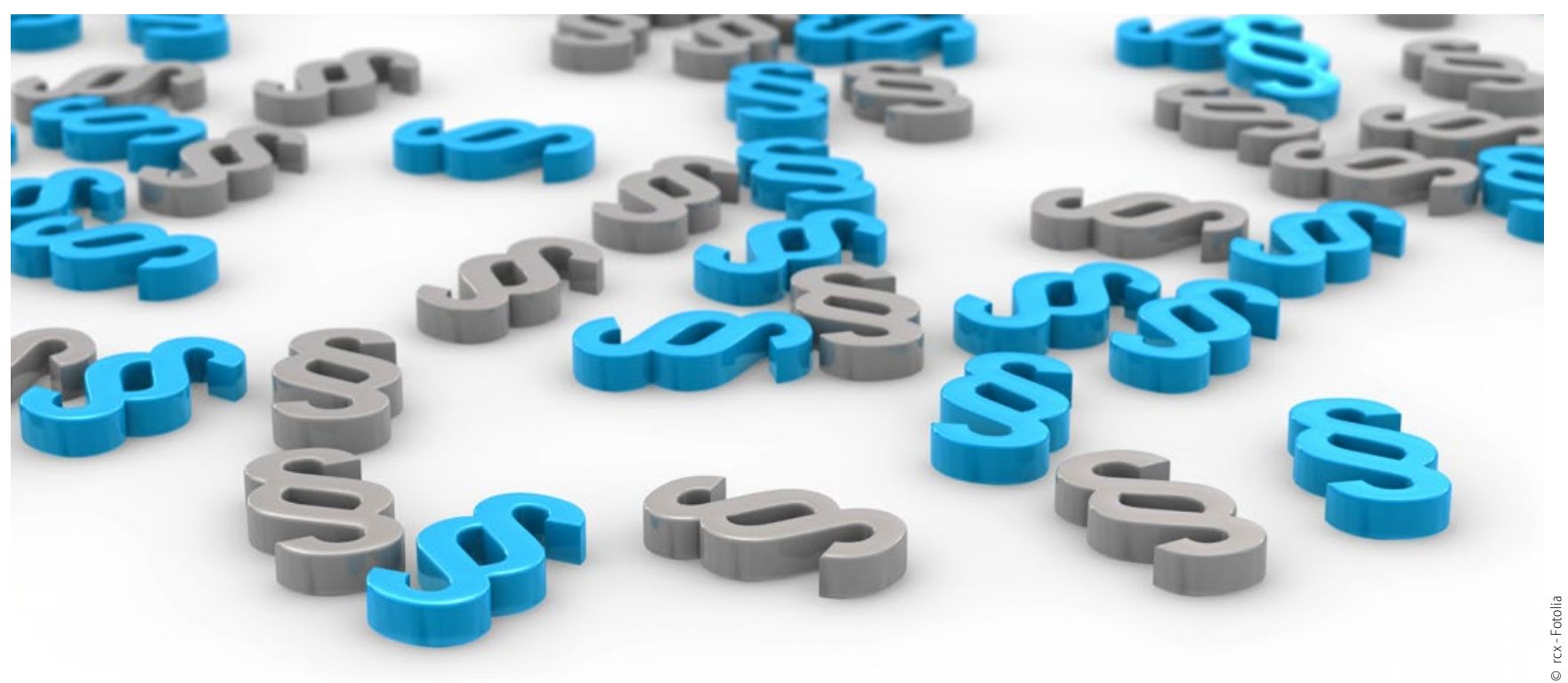

Sieg für kritische Berichterstattung in Bayern

\title{
Einstweilige Verfügung aufgehoben
}

\begin{abstract}
Der monatelange Rechtsstreit zwischen dem Vorsitzenden der Kassenzahnärztlichen Vereinigung Bayerns (KZVB), Dr. Janusz Rat, und der Fachjournalistin Anita Wuttke aus München ist durch einen Vergleich vor dem Oberlandesgericht München (OLG) beendet worden. Das OLG hat nach rechtlicher Würdigung des Falles dem zweifachen Vorwurf des Verfügungsklägers Rat widersprochen, die Journalistin habe sich in unzulässiger Weise die Meinung Dritter zu eigen gemacht. Nach Auffassung des Gerichts ist sie hier vielmehr vollumfänglich ihrer journalistischen Sorgfaltspflicht nachgekommen.
\end{abstract}

Anlass für den Rechtsstreit war ein Artikel in dieser Zeitschrift vom Juli 2015. Unter der Überschrift „Das Vertrauen fehlt“, setzte sich der Beitrag kritisch mit der Arbeit der beiden Vorsitzenden der KZVB, Dr. Janusz Rat und Dr. Stefan Böhm, auseinander. Anhand von Hintergrundinformation - zum Beispiel ein Interview mit dem Finanzausschussvorsitzenden der KZVB und aktuellen Geschehnissen aus der Vertreterversammlung der KZVB ging Wuttke der Frage nach, warum die Hälfte der Delegierten der Vertreterversammlung das Vertrauen in die Vorstandsarbeit verloren hat.

Rat verlangte nach Erscheinen des Artikels über seine Anwälte eine strafbewehrte Unterlassungserklärung sowohl von der Verfasserin als auch vom Fachverlag Springer Medizin. Darin wurde gefordert, es künftig zu unterlassen, bestimmte Aussagen des Finanzausschussvorsitzenden weiter zu verbreiten. Die Verfasserin lehnte mit Unterstützung des Bayerischen Journalistenverbandes ab, woraufhin Rats Rechtsvertreter eine einstweilige Verfügung beantragten, die dann auch vom Landgericht München erlassen wurde.

\section{Drei Viertel der Berufungskosten übernehmen die Vertragszahnärzte}

Der 18. Zivilsenat des Oberlandesgerichts München sah den Sachverhalt anders. Wegen der vorgerichtlichen Würdigung des Falls kam am Ende ein Vergleich zustande, bei dem wesentliche Inhalte des erstinstanzlichen Urteils aufgehoben wurden. Letztlich wurde der Beklagten lediglich aufgegeben, ein einziges Wort im Kontext mit dem Artikelinhalt nicht mehr zu verwenden.

An der Kostenverteilung wird deutlich, wie das Gericht den Fall beurteilte: Drei Viertel der Berufungskosten hat der Kläger Rat zu tragen, somit also die bayerischen Vertragszahnärzte, da das Verfahren vom Vorstandsvorsitzenden der KZV Bayerns angestrengt worden war.

Es ist nicht das erste Mal, dass die Bayerische KZV-Führungsriege Gerichte bemüht, um gegen missliebige Aussagen vorzugehen. Wegen der enormen Kosten solcher Verfahren besteht für einzelne Personen ein hohes finanzielles Risiko. In diesem Fall hatte die Journalistin glücklicherweise die Unterstützung des Bayerischen Journalistenverbandes. Ob sich an der Spitze der KZVB etwas ändert, können die bayerischen Zahnärzte bei den KZV-Wahlen in diesem Jahr entscheiden.

Dr. Reiner Zajitschek, Mitglied im FVDZ-Bundesvorstand

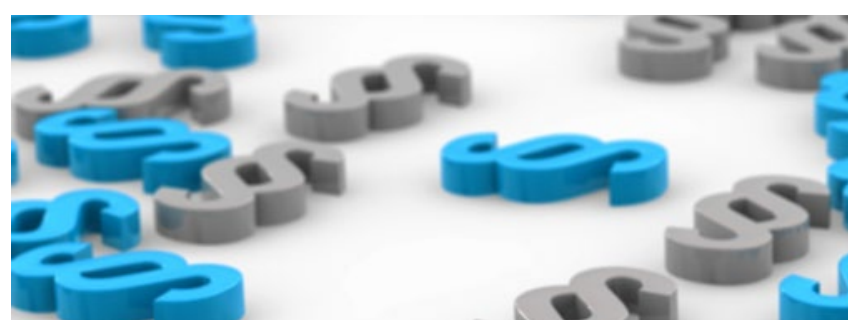

